\title{
Innervation patterns of sea otter (Enhydra lutris) mystacial follicle-sinus complexes
}

\author{
Christopher D. Marshall ${ }^{1,2}{ }^{*}$, Kelly Rozas ${ }^{1}$, Brian Kot ${ }^{1}$ and Verena A. Gill ${ }^{3}$ \\ ' Department of Marine Biology, Texas A\&M University, Galveston, TX, USA \\ ${ }^{2}$ Department of Wildlife and Fisheries Sciences, Texas A\&M University, TX, USA \\ ${ }^{3}$ Marine Mammals Management, U.S. Fish and Wildlife Service, Anchorage, Alaska, USA
}

Edited by:

Alfonso Fairén, University Miguel

Hernandez, Spain

\section{Reviewed by:}

Paul Manger, University of the

Witwatersrand, South Africa

George W. Huntley, Icahn School of

Medicine at Mount Sinai, USA

${ }^{*}$ Correspondence:

Christopher D. Marshall,

Department of Marine Biology,

Texas A\&M University, 200 Seawolf

Parkway, Bldg 3029 OCSB 253,

Galveston, TX 77551, USA

e-mail: marshalc@tamug.edu
Sea otters (Enhydra lutris) are the most recent group of mammals to return to the sea, and may exemplify divergent somatosensory tactile systems among mammals. Therefore, we quantified the mystacial vibrissal array of sea otters and histologically processed follicle-sinus complexes (F-SCs) to test the hypotheses that the number of myelinated axons per F-SC is greater than that found for terrestrial mammalian vibrissae and that their organization and microstructure converge with those of pinniped vibrissae. A mean of 120.5 vibrissae were arranged rostrally on a broad, blunt muzzle in 7-8 rows and 9-13 columns. The F-SCs of sea otters are tripartite in their organization and similar in microstructure to pinnipeds rather than terrestrial species. Each F-SC was innervated by a mean $1339 \pm 408.3$ axons. Innervation to the entire mystacial vibrissal array was estimated at 161,313 axons. Our data support the hypothesis that the disproportionate expansion of the coronal gyrus in somatosensory cortex of sea otters is related to the high innervation investment of the mystacial vibrissal array, and that quantifying innervation investment is a good proxy for tactile sensitivity. We predict that the tactile performance of sea otter mystacial vibrissae is comparable to that of harbor seals, sea lions and walruses.

Keywords: somatosensory system, peripheral nervous system, axon investment, vibrissae, F-SCs, comparative neurobiology, marine mammals, otters
Sea otters (Enhydra lutris) are the smallest and most recent group of marine mammals to return to marine habitats. They are thought to have arisen in the North Pacific during the Pleistocene (Leffler, 1964; Mitchell, 1966; Repenning, 1976) and have only become fully aquatic in the last $1-3$ million years (Berta and Sumich, 1999). Historically, sea otters occurred in near shore waters around the North Pacific rim from Hokkaido, Japan through the marine coastal areas of the Russian Far East and the Pacific coastal areas in the United States as far south as Baja California (Japan; Kenyon, 1975; Riedman and Estes, 1990). Three subspecies are recognized throughout this wide range: Southern sea otters (E.l. nereis), Northern sea otters (E.l. kenyoni), and Russian sea otters (E.l. lutris; Kenyon, 1975; Riedman and Estes, 1990). Sea otters play an important ecological role in structuring near shore benthic communities upon which they inhabit and forage (Estes and Palmisano, 1974; Estes and Duggins, 1995). Tactile senses are likely important during foraging dives in which they dig for infaunal bivalves, collect epifaunal invertebrates, or capture cephalopods and occasionally several species of fishes

Abbreviations: CT, Collagenous Trabeculae; DC, Dermal Capsule; DVN, Deep Vibrissal Nerve; F - SC, Follicle-Sinus Complex; GM, Glassy Membrane; HS, Hair Shaft; ICB, Inner Conical Body; LCS, Lower Cavernous Sinus; MNC, Merkel-Neurite Complex; MS, Mesenchymal Sheath; ORS, Outer Root Sheath; RS, Ring Sinus; RW, Ringwulst; SG, Sebaceous Gland; UCS, Upper Cavernous Sinus. near the sea-floor (Kenyon, 1975; Kvitek et al., 1988; Riedman and Estes, 1990). In general, the foraging ecology of all otters (Carnivora: Mustelidae: Lutrinae) is often categorized as either piscivorous mouth-oriented or invertebrate hand-oriented predation (Radinsky, 1968; Duplaix, 1984; Sivasothi and Nor, 1994; Jacques et al., 2009; Timm, 2013). These foraging categories manifest themselves as divergent feeding kinematics, biomechanics and performance (Timm, 2013) and were originally based on brain sulcal patterns (Radinsky, 1968) and morphological characters (Van Zyll de Jong, 1972).

Sea otters use their hands, digits and vibrissae to explore their environment, likely to assist them in identifying prey items. Vibrissae are specialized hair structures comprised of a hair-shaft surrounded by several blood-filled sinuses and technically termed a Follicle-Sinus Capsule (F - SC; Figure 2). Most of our knowledge regarding F - SC structure and function is based on terrestrial taxa (Davidson and Hardy, 1952; Melaragno and Montagna, 1953; Andres, 1966; Burgess and Perl, 1973; Gottschaldt et al., 1973; Halata, 1975, 1993; Halata and Munger, 1980; Rice et al., 1986, 1993, 1997; Brecht et al., 1997; Ebara et al., 2002), in which they are functionally divergent from other types of hair. Among aquatic mammals, afferent fibers from F-SCs respond best to vibrotactile stimuli (Dykes, 1974), but are used for both activetouch discrimination and hydrodynamic reception in pinnipeds (Stephens et al., 1973; Ling, 1977; Marshall et al., 2006; Hanke et al., 2013) and sirenians (Reep et al., 1998, 2001, 2002, 2011; 
Gaspard et al., 2013). Pinnipeds are known to possess the largest mystacial F-SCs (Ling, 1977). The hair shafts (HS) of many pinniped vibrissae are beaded in their appearance and show variation in this bumpy pattern (Ginter et al., 2010, 2012). This phenotype has been shown to decrease turbulent water flow over the HS (reviewed by Hanke et al., 2013). Furthermore, pinniped F-SCs diverge from terrestrial mammals in numerous ways, but most prominently in that they (1) possess a tripartite blood sinus system vs. a bipartite blood sinus system; (2) lack a superficial vibrissal nerve that innervates the apical regions of the F-SC; (3) possess a deep vibrissal nerve (DVN) that provides innervation to the entire F-SC and penetrates the external collagenous dermal capsule (DC) at the base of the follicle as opposed to entering the DC laterally near the lower cavernous sinus (LCS) and ring sinus (RS); (4) possess a greater number of axons per F - SC $(\sim 1000-1600$ in pinnipeds vs. $\sim 200$ in other mammals; Yablokov and Klezeval, 1969; Hyvärinen and Katajisto, 1984; Hyvärinen, 1989, 1995; Marshall et al., 2006). The F-SCs of sea otters remain unexplored, but as mammals that have recently returned to the sea, the functional and neural changes in vibrissal structure of otters during this transition are of evolutionary interest.

In lieu of comparable cortical and electrophysiological for sea otters, quantification of sea otter F-SC innervation can serve as a proxy for performance (George and Holliday, 2013). Quantifying the innervation of sea otter vibrissae can highlight somatosensory constraints and selection pressures of an aquatic environment. Is sea otter mystacial vibrissae morphology similar to terrestrial taxa, pinnipeds, a hybrid of both, or does it represent a completely novel microstructure and innervation? Due to their expanded vibrissal apparatus, we hypothesized that (1) the number of myelinated axons per F-SC, is greater than terrestrial mammalian vibrissae; and that (2) the microstructure of sea otter F-SCs converge with the vibrissae of pinnipeds rather than with those of terrestrial mammals, or a de novo organization.

\section{MATERIALS AND METHODS}

Whole bilateral mystacial vibrissal arrays $(N=6)$ of sea otters were collected during necropsies at the U.S. Fish and Wildlife Service's Marine Mammals laboratory in Anchorage, AK (USA). Samples were immersed in 10\% phosphate buffered formaldehyde. Mystacial vibrissal arrays were photographed and individual whiskers were counted and mapped (Figure 1). Lengths and diameters of the largest six individual vibrissae from each specimen were measured with digital calipers $(n=24)$. Sea otter F-SCs are relatively small, so six of the largest mystacial F-SCs were dissected from each specimen $(n=36)$ and frozen-sectioned either in the longitudinal plane or in cross-section using a Lipshaw 80A sliding stage microtome fitted with a circulating water freezing stage (Physitemp Instruments, Clifton, NJ) at $30 \mu \mathrm{m}$. Longitudinal sections and cross-sections were used for both neural and microstructural analyses. Sections were stained with either a modified Masson's trichrome stain or a modified Bodian silver stain (Armed Forces Institute of Pathology, 1968, 1994; Reep et al., 2001, 2002; Marshall et al., 2006). Histochemical stains were used because it was not possible to collect samples from remote

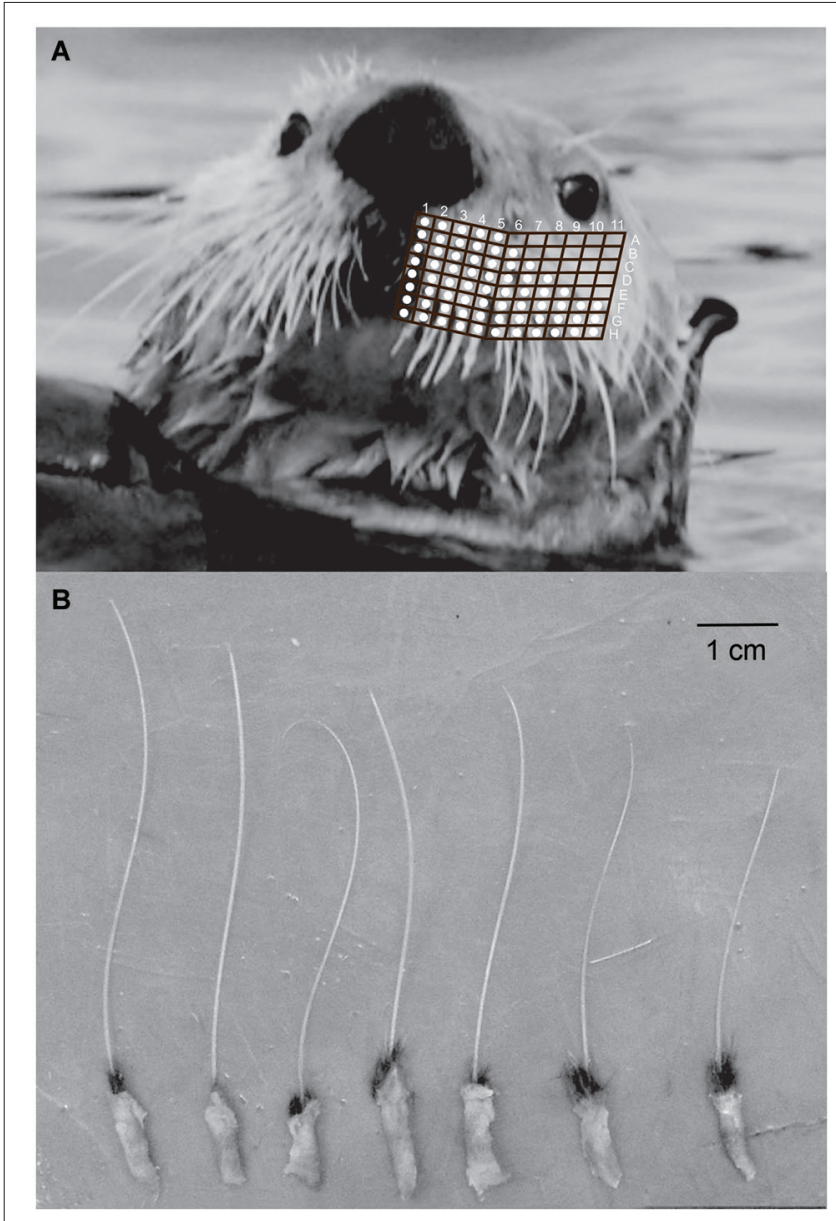

FIGURE 1 | (A) Sea otter mystacial vibrissae in vivo with overlain representative map of columns and rows of individual vibrissa. (B) Isolated mystacial vibrissae from rows $\mathrm{G}-\mathrm{H}$, columns 9-11.

locations in a manner that would have allowed immunolabeling techniques (e.g., Rice et al., 1997; Ebara et al., 2002; Sarko et al., 2007).

The following morphometric data were collected from histologically processed longitudinal sections: maximum F-SC length, maximum total sinus length (upper cavernous sinus [UCS] + ring sinus [RS] + lower cavernous sinus [LCS]), maximum RS width, maximum DC thickness, and maximum HS diameter at the level of the RS. The following morphometrics were collected from histologically processed cross-sections: maximum diameter of section (including DC), maximum longitudinal axis diameter of the HS, maximum perpendicular axis diameter of HS, DC thickness, and mesenchymal sheath (MS) thickness.

F - SC innervation patterns, myelinated axon counts, and identification of mechanoreceptor location were investigated using longitudinal sections and cross-sections stained with a modified Bodian silver stain, but also a trichrome stain. Myelinated axons were identified in cross-sections by their myelinated sheaths and were quantified midway along the length of the LCS following Marshall et al. (2006) and McGovern et al. (accepted). Axons 


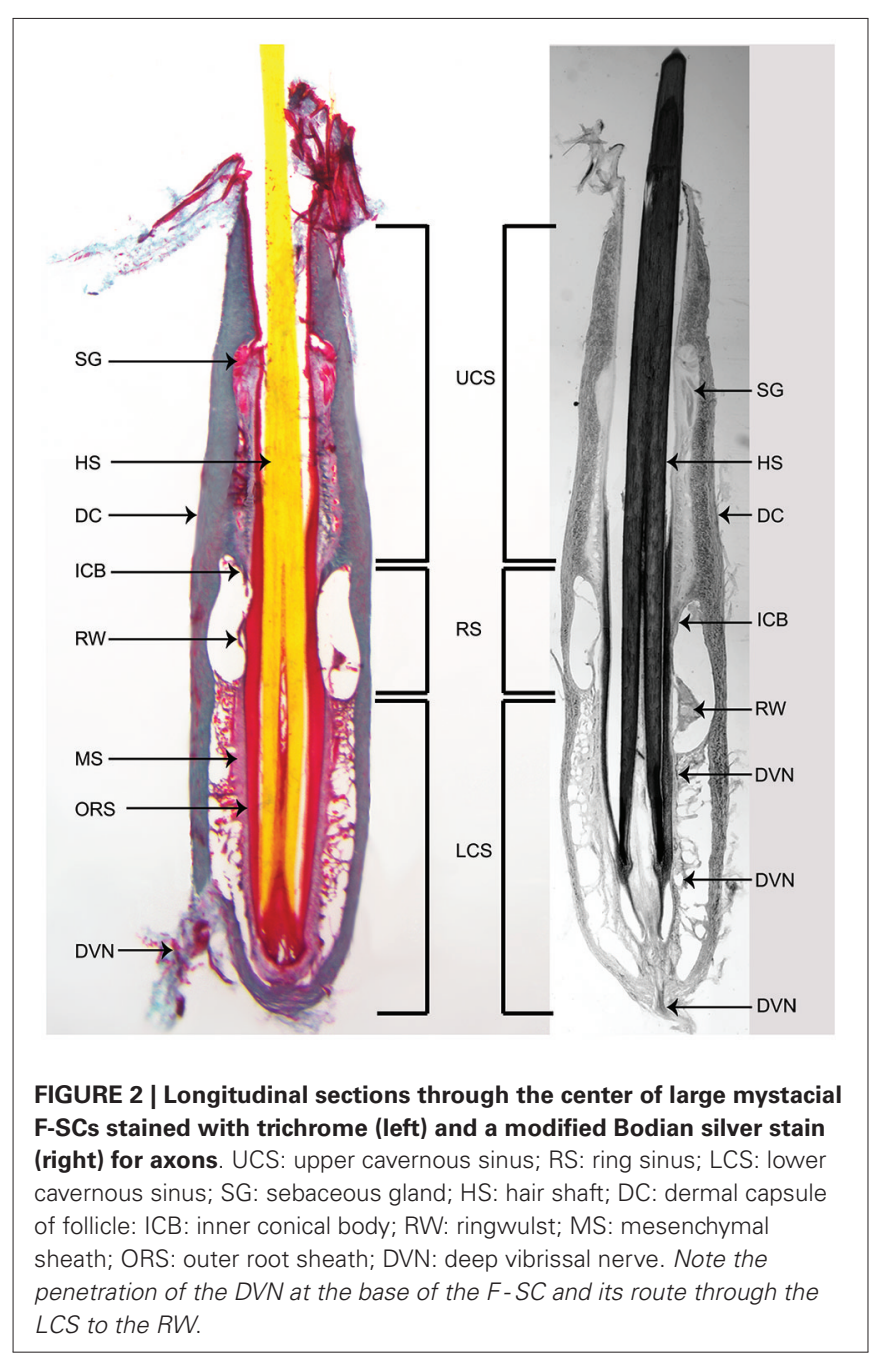

were counted at this location because axon numbers decrease above this location as the DVN ascends toward the RS (Rice et al., 1986). Conducting counts in this location is consistent with other studies, allowing a comparison of axon counts among species. Mystacial vibrissal innervation was quantified by (1) summing the axons in each cross-section; (2) averaging the axons from a minimum of four cross-sections from each F - SC from four individuals; (3) calculating the mean number of axons/F-SC from all six individuals; (4) calculating the mean number of vibrissae per vibrissal array; and (5) calculating the mean total innervation to the mystacial vibrissal array by multiplying the overall mean number of axons/F - SC by the mean number of vibrissae. Where possible we investigated the location of mechanoreceptors, but further characterization of sea otter mechanoreceptors was beyond the scope of this study.

\section{RESULTS}

The mean number of sea otter mystacial vibrissae was 120.5 $( \pm 7.29)$, which were arranged in 7-8 rows and 9-13 columns (Figure 1). Mystacial vibrissae are organized as macro- and micro-vibrissae and were located laterally and medially, respectively, within each mystacial array. The mean length of the largest
Table 1 | Cross-sectional F - SC morphometrics.

\begin{tabular}{|c|c|c|c|c|}
\hline & Mean & S.D. & Minimum & Maximum \\
\hline Max. diameter (mm) & 2.1 & 0.20 & 1.0 & 2.4 \\
\hline $\begin{array}{l}\text { Mean longitudinal } \\
\text { axis of } \mathrm{HS}(\mathrm{mm})\end{array}$ & 0.5 & 0.08 & 0.4 & 0.7 \\
\hline $\begin{array}{l}\text { Mean perpendicular } \\
\text { axis of } \mathrm{HS}(\mathrm{mm})\end{array}$ & 0.5 & 0.08 & 0.4 & 0.7 \\
\hline Ratio HS diameter & 1.0 & 0.04 & 0.9 & 1.1 \\
\hline Mean DC thickness (mm) & 0.2 & 0.04 & 0.1 & 0.3 \\
\hline Mean MS thickness (mm) & 0.1 & 0.04 & 0.1 & 0.3 \\
\hline Mean CT thickness (mm) & 0.3 & 0.05 & 0.1 & 0.4 \\
\hline
\end{tabular}

$N=25$.

Table 2 | Longitudinal F - SC morphometrics

\begin{tabular}{lrrcc}
\hline & Mean & S.D. & Minimum & Maximum \\
\hline Mean max F-SC length (mm) & 9.9 & 1.24 & 7.8 & 12.3 \\
Mean max. UCS length (mm) & 2.9 & 0.31 & 2.2 & 3.6 \\
Mean max. RS length (mm) & 1.8 & 0.21 & 1.3 & 2.1 \\
Total sinus length (mm) & 7.8 & 0.65 & 6.3 & 8.5 \\
Mean max. LCS length (mm) & 3.5 & 0.52 & 2.5 & 5.3 \\
\% UCS length to total & 39.4 & 3.19 & 33.7 & 45.9 \\
F-SC length & & & & \\
Mean max. RS width (mm) & 0.5 & 0.09 & 0.3 & 0.7 \\
Mean max. DC thickness (mm) & 0.4 & 0.07 & 0.16 & 0.5 \\
\hline
\end{tabular}

$N=22$.

mystacial vibrissal HS was $7.13 \pm 1.60 \mathrm{~mm}$, but wear on all $\mathrm{HS}$ was evident. Vibrissal HS were circular in cross-section. The ratio of two hair-shaft diameters $90^{\circ}$ to each other was $0.97 \pm 6.5$ and the ratio from histologically processed cross-sections was 1.00 $( \pm 0.04$; Table 1$)$. The HS profiles were smooth, that is they did not exhibit any beaded appearance.

Internally the F-SCs of sea otters exhibited a tripartite organization. Each F - SC was comprised of an UCS, RS, and a LCS (Figure 2). The UCS comprised $\sim 40 \%$ of the total F - SC length (Table 2). A relatively sizable Ringwulst (RW) was present in the RS (Figure 2). Thin collagenous trabeculae spanned both the UCS and the LCS, but not the RS. Sebaceous glands were located within the walls of the UCS, but no other types of glands were observed (Figures 2, 3).

Each F - SC was innervated by a DVN (Figures 2, 4), a branch of the infraorbital branch of the trigeminal nerve (CN V). The DVN penetrated the DC at, or near, the basal end of the F-SC. Upon entering the F-SC the DVN coursed apically, and branched into major bundles throughout the mid-UCS to innervate structures in the LCS, RS, RW and inner conical body (ICB). No innervation to the UCS by superficial vibrissal nerves, or other nerves, was observed. The mean number of myelinated axons innervating each F - SC was $1339 \pm 408.3$ axons. Since sea otters have a mean number of 120.5 vibrissae, the mean number of myelinated axons estimated to innervate the mystacial vibrissal array was 161,313 .

Mechanoreceptors were observed from the mid-LCS to the RS and ICB. Along its course the DVN, fibers were observed to branch off and course parallel to the glassy membrane (GM) and the MS (Figure 5A). Numerous branches were observed to 


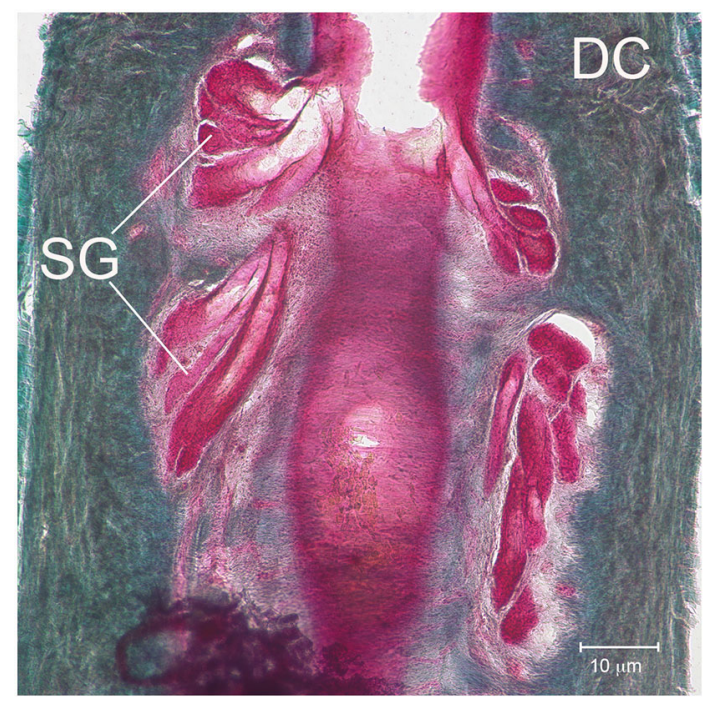

FIGURE 3 | Sebaceous glands. Detailed micrograph of SG near the apical region of the UCS and surrounded by the apical DC.

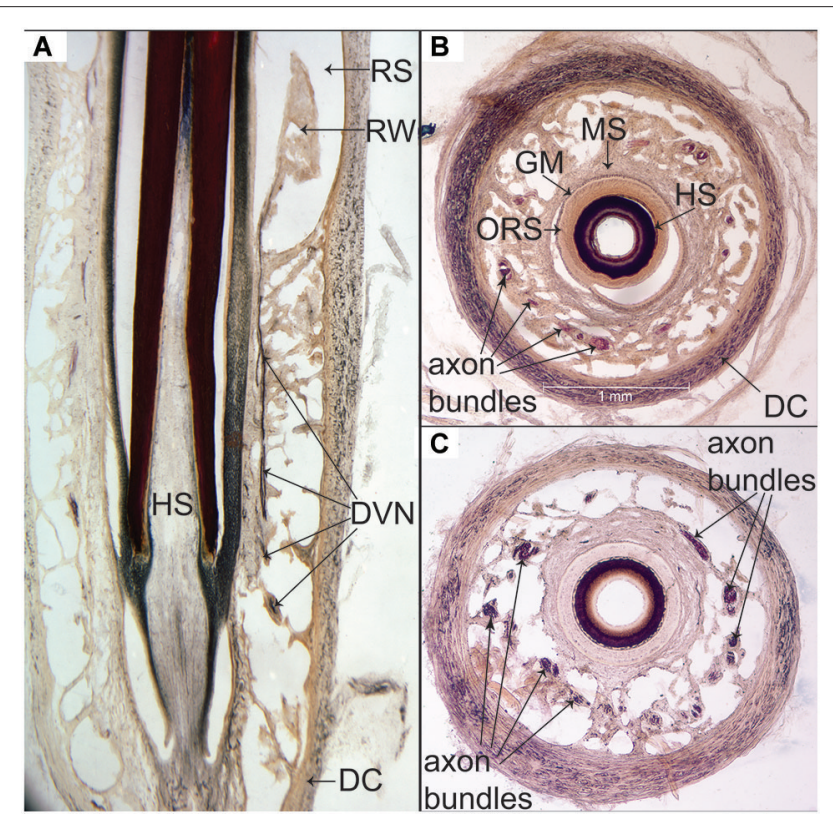

FIGURE 4 | Silver staining of sea otter F-SCs. (A) Longitudinal center section depicting the DVN ascending from the base of the LCS through the trabeculae and the MS to the RW within the RS. (B) Cross-section midway through the LCS showing the location and relative concentric organization of the DC, axon bundles within the trabeculae, MS, GM (glassy membrane), ORS and HS. (C) Silver stained axon bundles distributed throughout the trabeculae of the LCS.

leave these fibers and cross the GM and to supply presumptive mechanoreceptors in the outer root sheath (ORS), which appear to be Merkel-Neurite Complexes and lanceolate mechanoreceptors (Figure 5B). Mechanoreceptor type requires further confirmation using transmitted electron microscopy. Presumptive mechanoreceptors were always observed at the boundary of the
GM and ORS (Figure 5C) from the mid-LCS, to the RS and ICB.

\section{DISCUSSION}

Sea otters possess a bilateral mystacial vibrissal array that is oriented rostrally on a broad and blunt muzzle. This is in contrast to many pinnipeds that feed in the water column and possess more laterally placed mystacial vibrissal arrays. The forward orientation of sea otter vibrissae is ideal to interact with, and assist in identifying, epibenthic and infaunal prey. The mean number of individual mystacial vibrissae in sea otters reported here is consistent with numbers reported by Kenyon (1975) and the rostral orientation of mystacial vibrissae on the rostrum is consistent with other benthic foragers such as bearded seals (Erignathus barbatus; Marshall et al., 2006) and walruses (Fay, 1982; Kastelein and Mosterd, 1989; Marshall et al., 2006, 2008). Sea otters possess fewer vibrissae than bearded seals (Marshall et al., 2006) and walruses (Odobenus rosmarus; Fay, 1982), which is not surprising considering their small body size. Sea otter hairshafts lacked a beaded profile, and the circular cross-section is consistent with active touch performance rather than hydrodynamic reception, similar to these other benthic foragers. Sea otter F-SCs are similar to pinnipeds in that they are organized in a tripartite blood sinus system and possess common traits that pinnipeds exhibit, such as penetration of the DVN at the base of the follicle. In addition, the UCS of sea otters is relatively long and their UCS lacks innervation (i.e., a superficial vibrissal nerve as observed in terrestrial species). Although the long UCS of sea otters is similar to pinnipeds, it is relatively shorter than harbor seals (Phoca vitulina) and bearded seals, which are hypothesized to thermally protect the sensitive mechanoreceptors within the ICB, RS, and LCS from cold water (Dehnhardt et al., 1998; Mauck et al., 2000; Marshall et al., 2006; Erdsack et al., 2014). We propose a similar function in sea otters, which would also be advantageous for a small marine mammal with an elevated metabolic rate (Riedman and Estes, 1990; Yeates et al., 2007). Although the relative length of the UCS of sea otters is not as great as observed in harbor and bearded seals, sea otters do not experience extremely cold water as do these seals. The total innervation to the mystacial vibrissal array of sea otters (161,313 axons) is $\sim 50 \%$ less than bearded seals $(320,616$; Marshall et al., 2006), but this is only due to the fewer number of mystacial vibrissae, not a reduction in the number of axons/F SC. The innervation estimate to the entire mystacial vibrissal array in sea otters is nearly the same as ringed seals (Pusa hispida, 160,000; Hyvärinen et al., 2009) and northern elephant seals (Mirounga angustirostris, 159,000; McGovern et al., accepted). It should be noted that such estimates of innervation to the entire mystacial array may be overestimated since smaller FSCs may have fewer axons/F - SC as found in rodents (Lee and Woolsey, 1975; Welker and Van der Loos, 1986). However these relative measures are useful in a comparative context until more specific relationships between F - SC size and innervation become available for aquatic mammals. Overall, these results show that despite the recent return to the marine environment by sea otters, their F - SC microstructure and innervation have converged with their pinniped counterparts (Stephens et al., 1973; Hyvärinen 

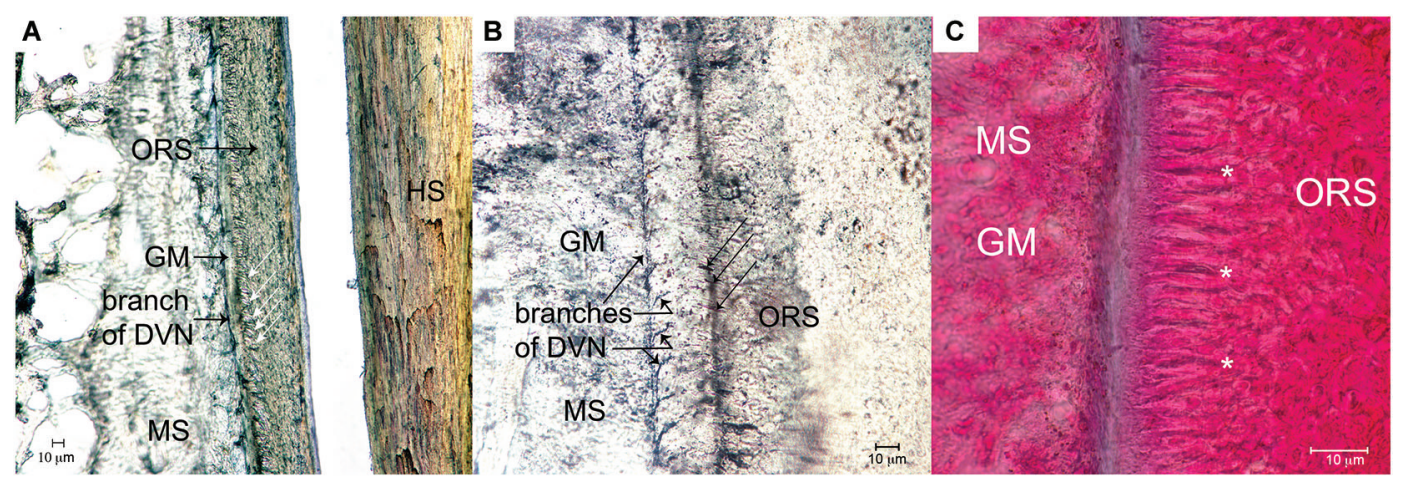

FIGURE 5 | Mechanoreceptors of the F-SC. (A) Longitudinal branch of the DVN coursing apically within the MS, but adjacent to the GM. White arrows show the location of presumptive Merkel-Neurite Complexes (MNCs) within the ORS adjacent to the GM (Bodian silver, 20X). (B) Longitudinal branch of the DVN coursing apically in the MS with numerous sub-branches crossing the GM to innervate presumptive lanceolate mechanoreceptors (black arrows) in the ORS (Bodian silver stain 40X). (C) Location of presumptive mechanoreceptors (asterisks) arranged in the ORS at the border of the GM (trichrome, 100X). and Katajisto, 1984; Hyvärinen, 1989, 1995; Marshall et al., 2006; Dehnhardt and Mauck, 2008; Hyvärinen et al., 2009). The selection pressures for an increased tactile capability for aquatic and benthic foraging likely resulted in the increased innervation of sea otter mystacial vibrissae compared to terrestrial mammals.

A comparative brain endocast study of sulcal patterns in all extant genera of otters by Radinsky (1968) reported two specializations of somatosensory cortex that relate to their tactile discrimination capabilities. Specifically, the coronal gyrus is enlarged in all otter genera relative to terrestrial carnivores. In addition, the brains of sea otters and clawless otters (Aonyx sp., including members formally in the genus Amblonyx and Paraonyx; BinindaEmonds et al. (1999) and Wilson and Reeder (2005)) also exhibit an expanded postcruciate gyrus. Although no electrophysiological mapping data of otters are available, electrophysiological mapping of the coronal gyrus in canids, felids, procyonids (Pinto Hamuy et al., 1956; Woolsey, 1958; Welker and Seidenstein, 1959; Welker and Campos, 1963; Welker et al., 1964), as well as northern fur seals (Callorhinus ursinus; Ladygina et al., 1992) demonstrate that this cortical region receives somatosensory projections from the head, and particularly from vibrissae. Furthermore, in Northern fur seals, afferent fibers from each mystacial vibrissa project to isolated and non-overlapping somatosensory cortex in the coronal gyrus (Ladygina et al., 1992). This cortical region in Northern fur seals is greatly expanded relative to the representation of other parts of the head, and is an example of cortical magnification found in somatosensory systems in a variety of specialized vertebrates (Catania, 2007). Likewise, the postcruciate gyrus receives somatosensory afferents from the forelimb (Pinto Hamuy et al., 1956; Woolsey, 1958; Welker and Seidenstein, 1959; Welker and Campos, 1963; Welker et al., 1964). These relationships appear to be a generalized pattern of mammalian brain organization.

Our data show that sea otter F-SC innervation supports Radinsky's hypothesis that the disproportionate expansion of the somatosensory regions in the coronal gyrus presents strong evidence of "an unusually high degree of development" of vibrissal afferents. Using comparative inference, the axons of sea otter F-SCs should project to the coronal gyrus in somatosensory cortex as observed in canids, felids, procyonids, and fur seals (Pinto Hamuy et al., 1956; Woolsey, 1958; Welker and Seidenstein, 1959; Welker and Campos, 1963; Welker et al., 1964; Ladygina et al., 1992). Such inferences are commonly used in paleoneuroanatomy and brain endocast data have been used to investigate the evolution of cortical regions in extinct and extant canids (e.g., Radinsky, 1967, 1968, 1973; Finarelli and Flynn, 2007; Lyras, 2009). This expansion of vibrissal innervation and corresponding somatosensory cortex also suggests increased tactile sensitivity to the vibrissae for all otters, as well as increased tactile sensitivity of the forelimbs for members of the genus Enhydra and Aonyx (Radinsky, 1968).

The use of mystacial vibrissae by pinnipeds to explore their environment is well known. Among pinnipeds, vibrissal function is perhaps best known for harbor seals (Phoca vitulina; reviewed by Hanke et al., 2013) and California sea lions (Zalophus californianus; Dehnhardt and Dücker, 1996). The lateral macrovibrissae of pinnipeds are used to explore large-scale environmental features and their medial micro-vibrissae are used for more refined and discrete tactile exploration (Dehnhardt and Kaminski, 1995; Dehnhardt and Dücker, 1996; Grant et al., 2013; Marshall et al., 2014). The resolution of tactile sensitivity, as characterized by a dimensionless Weber fraction, for harbor seals and California sea lions (Zalophus californianus) is approximately the same as for mammals using prehensile organs or monkeys using their hands (Dehnhardt, 1994; Dehnhardt and Kaminski, 1995; Dehnhardt and Dücker, 1996). Although it is less well known, it is clear that walruses can detect differences in surface area as small as $0.4 \mathrm{~cm}^{2}$ with their mystacial vibrissae, which is likely sensitive enough to distinguish among similar-sized prey types (Kastelein and van Gaalen, 1988). Based on the similarities of sea otter F-SCs in organization, innervation pattern, and presumptive projection of these axons to the coronal gyrus to somatosensory cortex as in pinnipeds, and electrophysiological mapping of fur seals and 
other mammalian taxa, we predict that the tactile performance of sea otter mystacial vibrissae should be at the level of harbor seals and California sea lions. Psychophysical testing of sea otter whisker sensitivity should be conducted to test this hypothesis. Clearly further investigation of the coronal, postcruciate and somatosensory cortical neuroanatomy and function are needed to further explore tactile performance in otters, as well as detailed data regarding these peripheral mechanoreceptors and associated structures.

Although much more is known regarding the innervation and function of terrestrial mammalian vibrissae, much of this knowledge is based on laboratory animal species. The limited comparative data regarding aquatic mammal vibrissae innervation indicate that aquatic and semi-aquatic mammals possess a greater innervation investment than terrestrial mammals (Hyvärinen, 1989, 1995; Hyvärinen et al., 2009). The F-SCs of rodents, rabbits, cats, and monkeys are innervated by approximately 100-200 myelinated axons (Halata, 1975; Lee and Woolsey, 1975; Halata and Munger, 1980; Rice et al., 1986, 1997; Ebara et al., 2002). This number is consistent for most terrestrial mammals. Pinniped innervation investment ranges 1000 to 1600 axons/F - SC. However, a more direct within Family aquatic vs. terrestrial comparison not only supports this pattern, but also now suggests a hierarchy of higher to lower innervation from fully- to semiaquatic to terrestrial species. For example, Australian water rats (a semi-aquatic species) possess 500 axons/F SC (Hydromys crysogaster; Dehnhardt et al., 1999) compared to laboratory rats $(\sim 100$ axons/F-SC), a terrestrial species. The number of axons/F-SC of sea otter mystacial vibrissae (1339), a fully-aquatic mustelid, is greater than semi-aquatic European river otters ( 500 ; Lutra lutra; Hyvärinen et al., 2009) and polecats (130; Mustela putorius), a terrestrial mustelid (Hyvärinen et al., 2009). The innervation of sea otter vibrissae is comparable to phocid seals and fits the fully-aquatic F-SC innervation investment pattern. Sirenians and odontocetes are exceptions to this pattern due to their adaptations for feeding on aquatic plants, and innovation of echolocation, respectively. However, as additional comparative data are collected from novel senses, such as the modification of vibrissae for electroreception in certain river dolphins (Czech-Damal et al., 2012), innervation investment from these senses may also fall within this pattern.

Continued investigations of aquatic mammals, including sea otters, are needed regarding segregation of information processing in trigeminal-thalamic projections to the coronal gyrus and cortical organization related to somatosensory systems. Such work will be important in elucidating aquatic sensory adaptations and the evolution of the mammalian somatosensory nervous system in secondarily aquatic mammals and tetrapods.

\section{AUTHOR CONTRIBUTIONS}

All authors had full access to all the data in the study and take responsibility for the integrity of the data and the accuracy of the data analysis. Study concept and design: Christopher D. Marshall. Acquisition of data: Kelly Rozas, Christopher D. Marshall, Verena A. Gill, Brian Kot. Analysis and interpretation of data: Christopher D. Marshall, Kelly Rozas. Drafting of the manuscript: Christopher D. Marshall. Critical revision of the manuscript for important intellectual content: Christopher D. Marshall, Kelly Rozas, Verena A. Gill, Brian Kot. Obtained funding: Christopher D. Marshall, Verena A. Gill.

\section{ACKNOWLEDGMENTS}

We appreciate the laboratory assistance of Kristin Worman from the U.S. Fish and Wildlife Service Office in Anchorage, AK (USA). We thank Roger Reep for numerous discussion regarding somatosensory systems and for critical comments that improved the manuscript. Specimens were collected under MMPA permit No. MA041309-5 issued to Gill in the U.S. Fish and Wildlife's Marine Mammals Management office. We also appreciate the support of the Texas Institute of Oceanography Undergraduate Fellowship to Kelly Rozas. Appreciation is given to Caitlin Sprowls and Erin Mattson for histological and microscopy assistance. The open access publishing fees for this article have been covered by the Texas A\&M University Online Access to Knowledge (OAK) Fund, supported by the University Libraries and the Office of the Vice President for Research. The findings and conclusions in this article are those of the authors and do not necessarily represent the views of the U.S. Fish and Wildlife Service.

\section{REFERENCES}

Andres, K. H. (1966). Uber die Feinstrukture der Rezeptoren an Sinushareen. $Z$. Zellforsch. 75, 365-399. doi: 10.1007/BF00407165

Armed Forces Institute of Pathology. (1968). Manual of Histologic Staining Methods. Washington, DC: American Registry of Pathology.

Armed Forces Institute of Pathology. (1994). Laboratory Methods in Histotechnology. Washington, DC: American Registry of Pathology.

Berta A., and Sumich, J. L. (1999). Marine Mammals: Evolutionary Biology. San Diego: Academic Press.

Bininda-Emonds, O. R. P., Gentleman, J. L., and Purvis, A. (1999). Building large trees by combining phylogenetic information: a complete phylogeny of the extant Carnivora (Mammalia). Biol. Rev. Camb. Philos. Soc. 74, 143-175. doi: 10. 1111/j.1469-185x.1999.tb00184.x

Brecht, M., Preilowski, B., and Merzenich, M. M. (1997). Functional architecture of the mystacial vibrissae. Behav. Brain Res. 84, 81-97. doi: 10.1016/s01664328(97)83328-1

Burgess, P. R., and Perl, E. R. (1973). "Cutaneous mechanoreceptors and nocioceptors," in Handbook of Sensory Physiology 2: Somatosensory systems, ed A. Iggo (Berlin: Springer-Verlag), 29-78.

Catania, K. C. (2007). "The evolution of the somatosensory system, clues from specialized species," in Evolution of Nervous Systems. Volume 3- Mammals, eds J. H. Kaas and L. A. Krubitzer (Amsterdam: Elsevier), 189-206.

Czech-Damal, N. U., Liebschner, A., Miersch, L., Klauer, G., Hanke, F. D., Marshall, C. D., et al. (2012). Electroreception in the Guiana dolphin (Sotalia guianensis). Proc. Biol. Sci. 279, 663-668. doi: 10.1098/rspb.2011. 1127

Davidson, P., and Hardy, M. H. (1952). The development of mouse vibrissae in vivo and in vitro. J. Anat. 86, 342-356.

Dehnhardt, G. (1994). Tactile size discrimination by a California sea lion (Zalophus californianus) using its mystacial vibrissae. J. Comp. Physiol. A 175, 791-800. doi: 10.1007/bf00191851

Dehnhardt, G., and Dücker, G. (1996). Tactual discrimination of size and shape by a California sea lion (Zalophus californianus). An. Learn. Behav. 24, 366-374. doi: 10.3758/bf03199008

Dehnhardt, G., Hyvärinen, H., Palviainen, A., and Klauer, G. (1999). Structure and innervation of the vibrissal follicle-sinus complex in the Australian water rat, Hydromys chrysogaster. J. Comp. Neurol. 411, 550-562. doi: 10.1002/(sici)10969861(19990906)411:4<550::aid-cne2>3.0.co;2-g

Dehnhardt, G., and Kaminski, A. (1995). Sensitivity of the mystacial vibrissae of harbor seals (Phoca vitulina) for size difference of actively touched objects. J. Exp. Biol. 198, 2317-2323. 
Dehnhardt, G., and Mauck, B. (2008). "Mechanoreception in secondarily aquatic vertebrates," in Sensory Evolution on the Threshold, eds G. M. Thewissen, S. Nummela (Berkeley: Berkeley University of California Press), 295-314.

Dehnhardt, G., Mauck, B., and Hyvärinen, H. (1998). Ambient temperature does not effect the tactile sensitivity of mystacial vibrissae in harbour seals. J. Exp. Biol. 201, 3023-3029.

Duplaix, N. (1984). "Otters," in Encyclopedia of Mammals, ed D. MacDonald (New York: Facts on File), 124-129.

Dykes, R. W. (1974). Afferent fibers from mystacial vibrissae of cats and seals. J. Neurophysiol. 38, 650-662.

Ebara, S., Kumatoto, K., Matsuura, T., Mazurkiewicz, J. E., and Rice, F. L. (2002). Similarities and differences in the innervation of mystacial vibrissal follicle-sinus complexes in the rat and cat: a confocal microscopic study. J. Comp. Neurol. 449, 103-119. doi: 10.1002/cne.10277

Erdsack, N., Dehnhardt, G., and Hanke, W. (2014). Thermoregulation of the vibrissal system in harbor seals (Phoca vitulina) and Cape fur seals (Arctocephalus pusillus pusillus). J. Exp. Mar. Biol. Ecol. 452, 111-118. doi: 10.1016/j.jembe.2013. 12.011

Estes, J. A., and Duggins, D. O. (1995). Sea otters and kelp forests in Alaska: generality and variation in a community ecological paradigm. Ecol. Monogr. 65, 75-100. doi: 10.2307/2937159

Estes, J. A., and Palmisano, J. F. (1974). Sea otters: the role in structuring nearshore communities. Science 185, 1058-1060. doi: 10.1126/science.185.4156. 1058

Fay, F. H. (1982). Ecology and Biology of the Pacific Walrus, Odobenus Rosmarus Divergens Illiger. Washington, DC: United States Department of Interior, Fish and Wildlife Service.

Finarelli, J. A., and Flynn, J. J. (2007). The evolution of encephalization in caniform carnivorans. Evolution 61, 1758-1772. doi: 10.1111/j.1558-5646.2007.00131.x

Gaspard, J. C., Bauer, G. B., Reep, R. L., Dziuk, K., Read, L., and Mann, D. A. (2013). Detection of hydrodynamic stimuli by the Florida manatee (Trichechus manatus latirostris). J. Comp. Physiol. A Neuroethol. Sens. Neural Behav. Physiol. 199, 441450. doi: 10.1007/s00359-013-0822-x

George, I. D., and Holliday, C. M. (2013). Trigeminal nerve morphology in Alligator mississippiensis and its significance for crocodyliform facial sensation and evolution. Anat. Rec. (Hoboken) 296, 670-680. doi: 10.1002/ar.22666

Ginter, C. C., DeWitt, T. J., Fish, F. E., and Marshall, C. D. (2012). Fused traditional and geometric morphometrics demonstrate pinniped whisker diversity. PLoS One 7:e34481. doi: 10.1371/journal.pone.0034481

Ginter, C. C., Fish, F. E., and Marshall, C. D. (2010). Morphological analysis of the bumpy profile of phocid vibrissae. Mar. Mamm. Sci. 26, 733-743. doi: 10.1111/ j.1748-7692.2009.00365.x

Gottschaldt, K. M., Iggo, A., and Young, D. W. (1973). Functional characteristics of mechanoreceptors in sinus hair follicles of the cat. J. Physiol. 235, 287-315.

Grant, R., Wieskotten, S., Wengst, N., Prescott, T., and Dehnhardt, G. (2013). Vibrissal touch sensing in the harbor seal (Phoca vitulina): how do seals judge size? J. Comp. Physiol. A Neuroethol. Sens. Neural Behav. Physiol. 199, 521-533. doi: 10.1007/s00359-013-0797-7

Halata, Z. (1975). "The mechanoreceptors of the mammalian skin ultrastructure and morphological classification," in Advances in Anatomy, Embryology and Cell Biology (Vol. 50), eds A. Brodal, W. Hild, J. van Limborgh, R. Ortmann, T. H. Schiebler, G. Tondury, E. Wolff (New York: Springer-Verlag), 5-75.

Halata, Z. (1993). Sensory innervation of the hairy skin (light and electron microscopic study). J. Invest. Dermatol. 101, 75S-81S. doi: 10.1111/1523-1747. ep 12362877

Halata, Z., and Munger, B. L. (1980). Sensory nerve endings in rhesus monkey sinus hairs. J. Comp. Neurol. 192, 645-663. doi: 10.1002/cne.901920403

Hanke, W., Wieskotten, S., Marshall, C., and Dehnhardt, G. (2013). Hydrodynamic perception in true seals (Phocidae) and eared seals (Otariidae). J. Comp. Physiol. A Neuroethol. Sens. Neural Behav. Physiol. 199, 421-440. doi: 10.1007/s00359012-0778-2

Hyvärinen, H. (1989). Diving into darkness: whiskers as sense organs fo the ringed seal (Phoca hispida saimensis). J. Zool. 218, 663-678. doi: 10.1111/j.1469-7998. 1989.tb05008.x

Hyvärinen, H. (1995). "Structure and function of the vibrissae of the ringed seal (Phoca hispida L)," in Sensory Systems of Aquatic Mammals, eds R. A. Kastelein, J. A. Thomas and P. A. Nachtigall (Woerden: De Spil), 429-445.

Hyvärinen, H., and Katajisto, H. (1984). Functional structure of the vibrissae of the ringed seal (Phoca hispida Schr.). Acta Zool. Fenn. 171, 17-30.
Hyvärinen, H., Palviainen, A., Strandberg, U., and Holopainen, I. (2009). Aquatic environment and differentiation of vibrissae: comparison of sinus hair systems of ringed seal, otter and pole cat. Brain Behav. Evol. 74, 268-279. doi: 10. $1159 / 000264662$

Jacques, H., Veron, G., Alary, F., and Aulagnier, S. (2009). The congo clawless otter (Aonyx congicus) (Mustelidae: Lutrinae): a review of its systematics, distribution and conservation status. Afr. Zool. 44, 159-170. doi: 10.3377/004. 044.0204

Kastelein, R. A., and Mosterd, P. (1989). The excavation technique for molluscs of Pacific Walrusses (Odobenus rosmarus divergens) under controlled conditions. Aq. Mamm. 15, 3-5.

Kastelein, R. A., and van Gaalen, M. A. (1988). The sensitivity of the vibrissae of a pacific walrus (Odobenus rosmarus). Aq. Mamm. 14, 123-133.

Kenyon, K. W. (1975). The Sea Otter in the Eastern Pacific Ocean. New York: Dover.

Kvitek, R. G., Fukayama, A. K., Anderson, B. S., and Grimm, B. K. (1988). Sea otter foraging on deep-burrowing bivalves in a California coastal lagoon. Mar. Biol. 98, 157-167. doi: 10.1007/bf00391191

Ladygina, T. F., Popov, V. V., and Supin, A. Y. (1992). Somatotopic projections in the cerebral cortex of the fur seal (Callorhinus ursinus). Acad. Sci. Moskow 17, 344-351.

Lee, K. J., and Woolsey, T. A. (1975). A proportional relationship between peripheral innervation density and neuron number in the somatosensory system of the mouse. Brain Res. 99, 349-353. doi: 10.1016/0006-8993(75)90035-9

Leffler, S. R. (1964). Fossil mammals from the Elk river formation, Cap Blanco, Oregon. J. Mamm. 45, 53-61. doi: 10.2307/1377294

Ling, J. K. (1977). "Vibrissae of marine mammals," in Functional Anatomy of Marine Mammals (Vol. 3), ed R. J. Harrison (London: Academic Press), 387-414.

Lyras, G. A. (2009). The evolution of the brain in Canidae (Mammalia: Carnivora). Scripta Geol. 139, 1-93

Marshall, C. D., Amin, H., Kovacs, K. M., and Lydersen, C. (2006). Microstructure and innervation of the mystacial vibrissal follicle-sinus complex in bearded seals, Erignathus barbatus (Pinnipedia: Phocidae). Anat. Rec. A Discov. Mol. Cell. Evol. Biol. 288A, 13-25. doi: 10.1002/ar.a.20273

Marshall, C. D., Kovacs, K. M., and Lydersen, C. (2008). Feeding kinematics, suction and hydraulic jetting capabilities in bearded seals (Erignathus barbatus). J. Exp. Biol. 211, 699-708. doi: 10.1242/jeb.009852

Marshall, C. D., Marsh, A., Wieskotten, S., Kot, B., Hanke, W., Hanke, F., et al. (2014). Feeding kinematics, suction and hydraulic jetting capabilities in harbor seals (Phoca vitulina). PLoS One 9:e86710. doi: 10.1371/journal.pone.0086710

Mauck, B., Eysel, U., and Dehnhardt, G. (2000). Selective heating of vibrissal follicles in seals (Phoca vitulina) and dolphins (Sotalia fluviatilis guianensis). J. Exp. Biol. 203, 2125-2131.

McGovern, K. A., Marshall, C. D., and Davis, R. W. (accepted). Are vibrissae viable sensory structures for prey capture in northern elephant seals, Mirounga angustirostris? Anat. Rec. doi: 10.1002/ar.2306100

Melaragno, H. P., and Montagna, W. (1953). The tactile hair follicles in the mouse. Anat. Rec. 115, 129-149. doi: 10.1002/ar.1091150202

Mitchell, E. D. (1966). Northeastern Pacific Pleistocene otters. J. Fish. Res. Bd. Can. 23, 1897-1911. doi: 10.1139/f66-177

Pinto Hamuy, T., Bromiley, R. B., and Woolsey, C. M. (1956). Somatic afferent areas I and II of the dog's cerebral cortex. J. Neurophysiol. 19, 485-499.

Radinsky, L. B. (1967). Relative brain size: a new measure. Science 155, 836-838. doi: 10.1126/science.155.3764.836

Radinsky, L. B. (1968). Evolution of somatic sensory specialization in otter brains. J. Comp. Neurol. 134, 495-506. doi: 10.1002/cne.901340408

Radinsky, L. B. (1973). Evolution of the canid brain. Brain Behav. Evol. 7, 169-202. doi: $10.1159 / 000124410$

Reep, R. L., Gaspard, J. C., Sarko, D., Rice, R. L., Mann, D. A., and Bauer, G. B. (2011). Manatee vibrissae: evidence for a "lateral line" function. Ann. N Y Acad. Sci. 1225, 101-119. doi: 10.1111/j.1749-6632.2011.05992.x

Reep, R. L., Marshall, C. D., and Stoll, M. L. (2002). Tactile hairs on the postcranial body in Florida manatees: a mammalian lateral line? Brain Behav. Evol. 59, 141154. doi: 10.1159/000064161

Reep, R. L., Marshall, C. D., Stoll, M. L., and Whitaker, D. M. (1998). Distribution and innervation of facial bristles and hairs in the Florida manatee (Trichechus manatus latirostris). Mar. Mamm. Sci. 14, 257-273. doi: 10.1111/j.1748-7692. 1998.tb00715.x

Reep, R. L., Stoll, M. L., Marshall, C. D., Homer, B. L., and Samuelson, D. A. (2001). Microanatomy of facial vibrissae in the Florida manatee: the basis 
for specialized sensory function and oripulation. Brain Behav. Evol. 58, 1-14. doi: 10.1159/000047257

Repenning, C. A. (1976). Enhydra and Enhydriodon from Pacific coast of North America. J. Res. U.S. Geol. Surv. 4, 305-315.

Rice, F. L., Fundin, B. T., Arviddson, J., Aldskogius, H., and Johansson, O. (1997). Comprehensive immunoflorescence and lectin binding analysis of vibrissal follicle sinus complex innervation in the mystacial pad of the rat. J. Comp. Neurol. 385, 149-184. doi: 10.1002/(sici)1096-9861(19970825)385:2<149::aidcnel>3.3.co; $2-x$

Rice, F. L., Kinnman, E., Aldskogius, H., Johansson, O., and Arvidsson, J. (1993). The innervation of the mystacial pad of the rat as revealed by PGP 9.5 immunofluorescence. J. Comp. Neurol. 337, 366-385. doi: 10.1002/cne. 903370303

Rice, F. L., Mance, A., and Munger, B. L. (1986). A comparative light microscopic analysis of the innervation of the mystacial pad: I, vibrissal follicles. J. Comp. Neurol. 252, 154-174. doi: 10.1002/cne.902520203

Riedman, M. L., and Estes, J. A. (1990). The sea otter (Enhydra lutris) behavior, ecology and natural history (Biological Report 90(14)). Washington, DC: U.S Dept. Interior, Fish Wildl. Serv., 126.

Sarko, D. K., Reep, R. L., Mazurkiewicz, J. E., and Rice, F. L. (2007). Adaptations in the structure and innervation of follicle-sinus complexes to an aquatic environment as seen in the Florida manatee (Trichechus manatus latirostris). J. Comp. Neurol. 504, 217-237. doi: 10.1002/cne.21446

Sivasothi, N., and Nor, B. H. M. (1994). A review of otters (Carnivora: Mustelidae: Lutrinae) in Malaysia and Singapore. Hydrobiologia 285, 151-170. doi: 10. 1007/bf00005663

Stephens, R. J., Beebe, I. J., and Poulter, T. C. (1973). Innervations of the vibrissae of the California sea lion Zalophus californianus. Anat. Rec. 176, 421-441. doi: 10. 1002/ar.1091760406

Timm, L. L. (2013). Feeding Biomechanics and Craniodental Morphology in Otters (Lutrinae). College Station: Texas A\&M Dissertation.

Van Zyll de Jong, C. G. (1972). A systematic review of the nearctic and neotropical river otters (Genus Lutra, Mustelidae, Carnivora). Royal Ontario Mus. Life Sci. Contrib. 80, 1-104. doi: 10.5962/bhl.title.52088

Welker, W. I., and Campos, G. B. (1963). Physiological significance of sulci in somatic sensory cerebral cortex in mammals of the family procyonidae. J. Comp. Neurol. 120, 19-36. doi: 10.1002/cne.901200103

Welker, W. I., Johnson, J. I., and Pubols, B. H. (1964). Some morphological and physiological characteristics of the somatic sensory system in racoons. Am. Zool. 4, 75-94. doi: 10.1093/icb/4.1.75
Welker, W. I., and Seidenstein, S. (1959). Somatic sensory representation in the cerebral cortex of the raccoon (Procyon lotor). J. Comp. Neurol. 111, 469-501. doi: 10.1002/cne.901110306

Welker, E., and Van der Loos, H. (1986). Quantitative correlation between barrelfield size and the sensory innervation of the whisker pad: a comparative study in six strains of mice bred for different patterns of mystacial vibrissae. J. Neurosci. 6, 3355-3373.

Wilson, D. E., and Reeder, D. M. (2005). Mammal Species of the World. A Taxonomic and Geographic Reference. 3rd Edn. Baltimore: Johns Hopkins University Press.

Woolsey, C. N. (1958). "Organization of somatic sensory and motor areas of the cerebral cortex," in Biological and Bio-Chemical Bases of Behavior, eds H. F. Harlow, C. N. Woolsey (Madison: University of Wisconsin Press), 63-81.

Yablokov, A., and Klezeval, G. (1969). "Whiskers of whales and seals and their distribution, structure and significance, Translation Bureau, foreign languages division, department of the secretary of state of Canada Fisheries research board of Canada, arctic biological station: ste. Anne de Bellevue, Quebec. translated from: Vibrissy kitoobraznykh i làstonogikh, ikh raspredelenie, stroenie znachenie," in Morfologicheskie Osobennosti Vodnikh Mlekopitayushchikh, ed S. E. Kleinenberg (Moscow: Izdatel'stvo, Naukall), 48-81.

Yeates, L. C., Williams, T. M., and Fink, T. L. (2007). Diving and foraging energetics of the smallest marine mammal, the sea otter (Enhydra lutris). J. Exp. Biol. 210, 1960-1970. doi: 10.1242/jeb.02767

Conflict of Interest Statement: The authors declare that the research was conducted in the absence of any commercial or financial relationships that could be construed as a potential conflict of interest.

Received: 18 August 2014; paper pending published: 30 September 2014; accepted: 11 October 2014; published online: 29 October 2014.

Citation: Marshall CD, Rozas K, Kot B and Gill VA (2014) Innervation patterns of sea otter (Enhydra lutris) mystacial follicle-sinus complexes. Front. Neuroanat. 8:121. doi: 10.3389/fnana.2014.00121

This article was submitted to the journal Frontiers in Neuroanatomy.

Copyright (c) 2014 Marshall, Rozas, Kot and Gill. This is an open-access article distributed under the terms of the Creative Commons Attribution License (CC BY). The use, distribution and reproduction in other forums is permitted, provided the original author(s) or licensor are credited and that the original publication in this journal is cited, in accordance with accepted academic practice. No use, distribution or reproduction is permitted which does not comply with these terms. 